\title{
Temperature dependent photoreflectance study of Cu2SnS3 thin films produced by pulsed laser deposition
}

Raadik, T.; Grossberg, M.; Krustok, J.; Kauk-Kuusik, M.; Crovetto, Andrea; Ettlinger, Rebecca Bolt; Hansen, O.; Schou, Jørgen

Published in:

Applied Physics Letters

Link to article, DOI:

$10.1063 / 1.4990657$

Publication date:

2017

Document Version

Publisher's PDF, also known as Version of record

Link back to DTU Orbit

Citation (APA):

Raadik, T., Grossberg, M., Krustok, J., Kauk-Kuusik, M., Crovetto, A., Ettlinger, R. B., Hansen, O., \& Schou, J. (2017). Temperature dependent photoreflectance study of Cu2SnS3 thin films produced by pulsed laser deposition. Applied Physics Letters, 110(26), [261105]. https://doi.org/10.1063/1.4990657

\section{General rights}

Copyright and moral rights for the publications made accessible in the public portal are retained by the authors and/or other copyright owners and it is a condition of accessing publications that users recognise and abide by the legal requirements associated with these rights.

- Users may download and print one copy of any publication from the public portal for the purpose of private study or research.

- You may not further distribute the material or use it for any profit-making activity or commercial gain

- You may freely distribute the URL identifying the publication in the public portal 


\section{Temperature dependent photoreflectance study of $\mathrm{Cu}_{2} \mathrm{SnS}_{3}$ thin films produced by pulsed laser deposition}

T. Raadik, M. Grossberg, J. Krustok, M. Kauk-Kuusik, A. Crovetto, R. Bolt Ettlinger, O. Hansen, and J. Schou

Citation: Appl. Phys. Lett. 110, 261105 (2017); doi: 10.1063/1.4990657

View online: http://dx.doi.org/10.1063/1.4990657

View Table of Contents: http://aip.scitation.org/toc/apl/110/26

Published by the American Institute of Physics

\section{Articles you may be interested in}

A highly efficient element for generating elliptic perfect optical vortices

Applied Physics Letters 110, 261102 (2017); 10.1063/1.4990394

Directly generating orbital angular momentum in second-harmonic waves with a spirally poled nonlinear photonic crystal

Applied Physics Letters 110, 261104 (2017); 10.1063/1.4990527

Corrugated plasmonic cavity for enhanced intersubband photodetection

Applied Physics Letters 110, 261103 (2017); 10.1063/1.4990526

As-grown two-dimensional $\mathrm{MoS}_{2}$ based photodetectors with naturally formed contacts

Applied Physics Letters 110, 261109 (2017); 10.1063/1.4990968

Optical nanoscopy with contact Mie-particles: Resolution analysis

Applied Physics Letters 110, 261107 (2017); 10.1063/1.4989687

4.5 W supercontinuum generation from 1017 to $3438 \mathrm{~nm}$ in an all-solid fluorotellurite fiber Applied Physics Letters 110, 261106 (2017); 10.1063/1.4990681

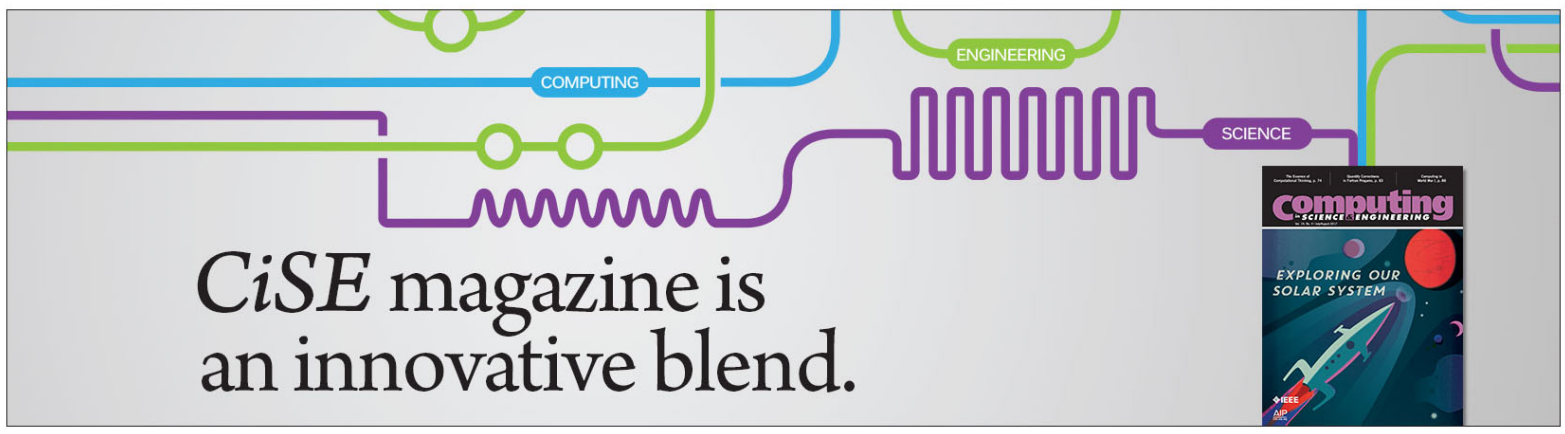




\title{
Temperature dependent photoreflectance study of $\mathrm{Cu}_{2} \mathrm{SnS}_{3}$ thin films produced by pulsed laser deposition
}

\author{
T. Raadik, ${ }^{1, a)}$ M. Grossberg, ${ }^{1}$ J. Krustok, ${ }^{1}$ M. Kauk-Kuusik, ${ }^{1}$ A. Crovetto, ${ }^{2}$ R. Bolt Ettlinger, ${ }^{3}$ \\ O. Hansen, ${ }^{2}$ and J. Schou ${ }^{3}$ \\ ${ }^{1}$ Tallinn University of Technology, Ehitajate tee 5, 19086 Tallinn, Estonia \\ ${ }^{2}$ DTU Nanotech, Technical University of Denmark, DK-2800 Kgs. Lyngby, Denmark \\ ${ }^{3}$ DTU Fotonik, Technical University of Denmark, DK-4000 Roskilde, Denmark
}

(Received 27 April 2017; accepted 15 June 2017; published online 28 June 2017)

\begin{abstract}
The energy band structure of $\mathrm{Cu}_{2} \mathrm{SnS}_{3}$ (CTS) thin films fabricated by pulsed laser deposition was studied by photoreflectance spectroscopy (PR). The temperature-dependent PR spectra were measured in the range of $T=10-150 \mathrm{~K}$. According to the Raman scattering analysis, the monoclinic crystal structure $(\mathrm{C} 1 \mathrm{c} 1)$ prevails in the studied CTS thin film; however, a weak contribution from cubic CTS (F-43m) was also detected. The PR spectra revealed the valence band splitting of CTS. Optical transitions at $E_{A}=0.92 \mathrm{eV}, \mathrm{E}_{\mathrm{B}}=1.04 \mathrm{eV}$, and $E_{C}=1.08 \mathrm{eV}$ were found for monoclinic CTS at low-temperature $(T=10 \mathrm{~K})$. Additional optical transition was detected at $E_{A}^{C}=0.94 \mathrm{eV}$, and it was attributed to the low-temperature band gap of cubic CTS. All the identified optical transition energies showed a blueshift with increasing temperature, and the temperature coefficient $d E / d T$ was about 0.1 meV/K. Published by AIP Publishing. [http://dx.doi.org/10.1063/1.4990657]
\end{abstract}

There is a continuous search for alternative absorber materials with an excellent environmental profile for highly efficient photovoltaics. One possible candidate is $\mathrm{Cu}_{2} \mathrm{SnS}_{3}$ (CTS) that is a direct-bandgap p-type semiconductor with a high absorption coefficient $\left(10^{4} \mathrm{~cm}^{-1}\right)$ consisting of abundantly available and non-toxic elements. The best solar cell efficiency obtained from monoclinic CTS is $4.63 \%{ }^{1}$

$\mathrm{Cu}_{2} \mathrm{SnS}_{3}$ has been reported to crystallize in three different polymorphs: cubic (F-43m), ${ }^{2,3}$ tetragonal (I-42m), ${ }^{2,4}$ and monoclinic $(\mathrm{C} 1 \mathrm{c} 1)^{5-8}$ depending on the synthesis temperature where higher temperature leads to a higher degree of symmetry of the unit cell. These polymorphs are barely distinguishable by XRD, whereas Raman spectroscopy has been proved to be more sensitive for determining the phase composition of CTS. It has been shown that CTS synthesized at temperatures below $500-550{ }^{\circ} \mathrm{C}$ adopts a cubic or a tetragonal crystal structure, while at higher temperatures, a monoclinic structure is obtained. ${ }^{2,5,9}$ Additionally, other groups have mainly observed the monoclinic phase at 520-570 $\mathrm{C},{ }^{7,10,11}$ but it has also been reported at lower temperatures, ${ }^{9}$ and the exact temperature might depend on the state of the precursors and the details of the annealing system. Monoclinic CTS absorbers for solar cells have to be grown $\mathrm{Cu}$-poor to avoid alloying with metallic $\mathrm{Cu}_{3} \mathrm{SnS}_{4}{ }^{12}$ and at the same time, the Sn-rich composition may lead to the formation of $\mathrm{Cu}_{2} \mathrm{Sn}_{3} \mathrm{~S}_{7}{ }^{13}$

The theoretical density functional theory (DFT) calculations predict a triple optical absorption onset for monoclinic CTS, ${ }^{10,14}$ indicating a valence band splitting. From the DFT calculations, de Wild et al. ${ }^{10}$ found the theoretical bandgap value of $0.76 \mathrm{eV}$ for monoclinic CTS and the valence band splitting at the $\Gamma$-point between the topmost and the second valence band of $\Delta_{l}=0.10 \mathrm{eV}$ and between the topmost and

\footnotetext{
${ }^{\text {a) }}$ Author to whom correspondence should be addressed: taavi.raadik@ttu.ee. Tel.:+372620 3210. Fax: +3726203367.
}

the third valence band of $\Delta_{2}=0.15 \mathrm{eV}$. Experimentally obtained results, calculated from the absorption spectrum, were slightly different. The room temperature bandgap energy value for monoclinic CTS was found to be $E_{A}$ $=0.96 \mathrm{eV}$, whereas the onset between the main and the second and third uppermost valence bands of $\Delta_{l}=0.11 \mathrm{eV}$ and $\Delta_{2}=0.16 \mathrm{eV}$, respectively, is in good accordance with theoretical calculations. Theoretical calculations by using the DFT method of the CTS band structure have also been done by Crovetto et al. ${ }^{14}$ They reported a double absorption onset in monoclinic CTS and showed that the double onset is related to the intrinsic nature of this compound and not to other CTS phases or compounds. They found a theoretical bandgap value of $E_{A}=0.83 \mathrm{eV}$ for monoclinic CTS and the splitting between the main and the second and third uppermost valence bands of $\Delta_{1}=0.12 \mathrm{eV}$ and $\Delta_{2}=0.16 \mathrm{eV}$, respectively. These values are in good accordance with the results obtained by de Wild. ${ }^{10}$ A similar bandgap value of $E_{A}=0.84 \mathrm{eV}$, found from theoretical hybrid nonlocal exchange-correlation functional (HSE) calculations, has been reported also by Zhai et al. ${ }^{15}$ Crovetto et al. ${ }^{14}$ have also reported the experimental values of optical transition energies determined from absorption spectra at room temperature. Their results showed the bandgap energy $E_{A}=0.91 \mathrm{eV}$ and the second optical transition at $0.99 \mathrm{eV}$, which is related to $E_{B}$ transition, while the theoretically predicted third transition $E_{C}$ was not seen in this study. Similar to de Wild's results, theoretical transition energies calculated by Crovetto et al. $^{14}$ are much smaller compared with experimental results. As it was mentioned before, CTS has three different polymorphs: besides monoclinic, there are also a cubic and a tetragonal crystal structure that have bandgap energy values higher than monoclinic CTS. Fernandes et al. ${ }^{16}$ have reported an experimental bandgap value of $E_{A}^{C}=0.96 \mathrm{eV}$ for cubic CTS and $E_{A}^{T}=1.35 \mathrm{eV}$ for tetragonal CTS. On the other hand, Guan et al. ${ }^{3}$ have found bandgap energies of 
$E_{\mathrm{A}}^{C}=1.19 \mathrm{eV}$ and $E_{A}^{T}=1.05 \mathrm{eV}$, for cubic and tetragonal CTS, respectively. The contradictory data about the band gap energies of the different polymorphs of CTS available in the literature were one of the main motivations for this study.

In this report, the modulation spectroscopy, namely, a photoreflectance method, is used to study the energy band structure of CTS. Photoreflectance (PR) spectroscopy has proven to be a useful tool to characterize the optical properties of semiconductors, especially the bandgap energy and valence band splittings. ${ }^{17-20}$

The thin film of CTS with a thickness of $80 \mathrm{~nm}$ was grown by pulsed laser deposition (PLD) on a Mo covered glass substrate with $7 \mathrm{~ns}$ laser pulses at $355 \mathrm{~nm}$ from a Q-switched, frequency-tripled $1064 \mathrm{~nm}$ Nd:YAG laser (Coherent). The laser incidence angle on the target was $45^{\circ}$, the fluence was $1.6 \mathrm{~J} / \mathrm{cm}^{2}$, and the target-substrate distance was $4 \mathrm{~cm}$. The fluence had been adjusted to yield the correct $\mathrm{Cu}: \mathrm{Sn}$ ratio in the films. ${ }^{21}$ The target was a multiphase sintered pellet made from binary sulfides mixed for an average target composition of 2Cu:Sn:3S (PVD products; manufactured by Testbourne, Ltd.). The target sintering temperature was about $750^{\circ} \mathrm{C}$, and the resulting pellet had microdomains of copper sulfides, tin sulfides, and copper tin sulfides. The deposition took place at room temperature in vacuum $\left(p<3 \times 10^{-6} \mathrm{mbar}\right)$. The target was rotated while the laser beam was moved in a raster pattern to improve film uniformity. In order to obtain the monoclinic CTS, the film was annealed with excess $\mathrm{S}$ in a graphite box inside a tube furnace with an $\mathrm{N}_{2}$ atmosphere at $570^{\circ} \mathrm{C}$ for 10 min using a slow ramp-up rate of $2{ }^{\circ} \mathrm{C} / \mathrm{min}$ to $570^{\circ} \mathrm{C}$ and natural cooling. Before annealing, the material is an amorphous mixture of $\mathrm{Cu}, \mathrm{Sn}$, and $\mathrm{S}$ according to XRD and energy dispersive $\mathrm{x}$ ray $(\mathrm{EDX})$ on samples made in the same way as the ones studied here.

Before the PR spectroscopy study, Raman measurements were made at room temperature with a high-resolution micro-Raman spectrometer Horiba Jobin Yvon HR800 equipped with a multichannel CCD detection system in the backscattering configuration. The incident Nd-YAG laser light with $\lambda=532 \mathrm{~nm}$ and a spot size of $10 \mu \mathrm{m}$ in diameter was used for excitation. The PR measurements were made with a traditional setup, ${ }^{18}$ where the $f=64 \mathrm{~cm}$ grating monochromator together with a $250 \mathrm{~W}$ halogen bulb was used as a primary beam and a $70 \mathrm{~mW}$ He-Cd laser $(\lambda=441 \mathrm{~nm})$ as a secondary beam. The reflectance signal at $120 \mathrm{~Hz}$ was detected using a Ge detector with a lock-in amplifier in the spectral range from 0.85 to $1.15 \mathrm{eV}$. In order to make low-temperature PR measurements, the CTS sample under study was glued with a cryogenic grease onto the cold finger of the closed-cycle He cryostat.

The Raman spectrum of CTS together with the fitting result is presented in Fig. 1. The Raman spectrum was fitted using Lorentzian line shape functions to resolve the peaks since it can be seen that the dominating Raman peaks at about $290 \mathrm{~cm}^{-1}$ and $350 \mathrm{~cm}^{-1}$ have an asymmetric shape. Based on the available information in the literature about the Raman modes of CTS polymorphs, ${ }^{2,11,16}$ our Raman spectra indicate that the monoclinic CTS prevails in the studied film showing the most intense peak at $292 \mathrm{~cm}^{-1}$ and other peaks at $222,254,317,350$, and $371 \mathrm{~cm}^{-1}$. However, the cubic

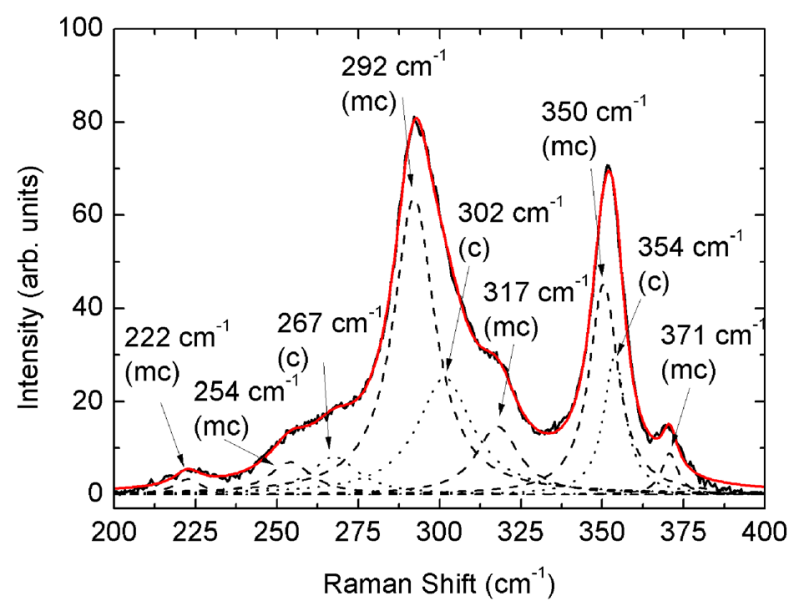

FIG. 1. Room temperature Raman spectrum of the CTS thin film together with fittings. (mc) indicates monoclinic - and (c) a cubic phase. The red line is the sum of the fitting.

CTS phase was also found with the corresponding, weaker Raman peaks detected at 267, 302, and $354 \mathrm{~cm}^{-1}$. . $^{11,16}$

For determining the energy band structure of CTS, photoreflectance spectroscopy was used. In PR spectroscopy, a periodic perturbation, in our case the modulated laser beam, produces sharp derivative-like features in the optical response of the sample, making this method very useful for detecting transitions having very weak oscillator strengths. The derivative nature of the spectra enhances the features in the energy region of interband transitions at the critical point in the Brillouin zone. For CTS, the valence band states arise due to the hybridization of the $\mathrm{Cu} 3 \mathrm{~d}$ orbitals and the $\mathrm{S} 3 \mathrm{p}$ orbitals. The conduction band minimum is composed of $\mathrm{Sn}$ $5 \mathrm{~s}$ and $\mathrm{S} 3 \mathrm{p}$ components. ${ }^{22}$ At the $\Gamma$ point, the degeneracy of the three uppermost valence bands is lifted due to the combination of a crystal field and a spin orbit splitting. The first is induced by the lowered symmetry compared to the zinc blende structure which mainly stems from the tetragonal distortion of the unit cell due to the anion displacement. Photoreflectance measurements enable us to detect optical transitions related to the three valence bands.

The photoreflectance spectrum measured at $10 \mathrm{~K}$ together with fittings is shown in Fig. 2. The three derivative-like features corresponding to the multiple optical transitions of CTS that result from the band gap and valence band splittings are clearly visible in the reflectance spectrum. A weak feature at around $0.94 \mathrm{eV}$ was also detected. Each PR spectrum has been analyzed by the low-field line-shape function with a third derivative functional form, developed by Aspnes ${ }^{23}$

$$
\frac{\Delta R}{R}=\sum_{j=1}^{n} \operatorname{Re}\left[A_{j} e^{i \varphi_{j}}\left(E-E_{g, j}+i \Gamma_{j}\right)^{-m}\right],
$$

where $E$ is the photon energy and $A_{j}, \varphi_{j}, E_{g, j}$, and $\Gamma_{j}$ are the amplitude, phase, optical transition energy, and broadening parameter of the spectrum of the $j$ th structure, while $n$ is the number of critical points, in our case 4 . The exponent $m$ depends on the type of the critical point, and determining its proper value is of particular importance in analyzing PR spectra. $m=2.5$, corresponding to a three-dimensional critical point, was used for the fitting of all PR spectra. In order 


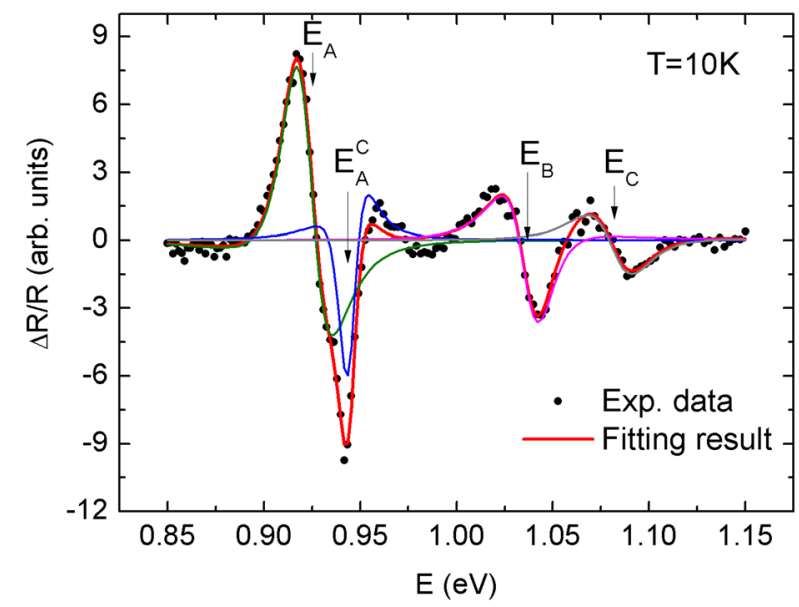

FIG. 2. Photoreflectance spectrum of CTS at $10 \mathrm{~K}$ together with fittings with Eq. (1). From the fittings, three optical transitions of monoclinic CTS, $E_{A}$, $E_{B}$ and $E_{C}$, were determined. An additional optical transition $E_{A}^{C}$ was attributed to the band gap of cubic CTS.

to study the temperature dependencies of the observed optical transitions, PR measurements were performed in the temperature range of $T=10-150 \mathrm{~K}$.

The detailed fitting with Eq. (1) revealed four optical transitions at $E_{A}=0.92 \mathrm{eV}, E_{B}=1.04 \mathrm{eV}, E_{C}=1.08 \mathrm{eV}$, and $E_{A}^{C}=0.94 \mathrm{eV}$. The latter optical transition $E_{A}^{C}$ is attributed to the bandgap energy of cubic CTS since the Raman spectra revealed the presence of the cubic CTS phase in the studied film. Indeed, Fernandes et al. ${ }^{16}$ have found that the cubic phase of CTS has a bandgap of $E_{A}^{C}=0.96 \mathrm{eV}$. A slightly higher value of $E_{A}^{C}=0.98 \mathrm{eV}$ has been reported by Zhai et $a l .{ }^{15}$ According to the literature, we can attribute $\mathrm{E}_{\mathrm{A}}, \mathrm{E}_{\mathrm{B}}$, and $E_{C}$ to the bandgap and valence band splitting of the monoclinic CTS, and the band structure can be seen in Fig. 3. Experimentally determined offsets between optical transition energies $E_{A}, E_{B}$, and $E_{C}$ were $\Delta_{l}=0.12 \mathrm{eV}$ and $\Delta_{2}=0.16 \mathrm{eV}$, and they are in good accordance with the results of the theoretical calculations. ${ }^{10,14}$

Interestingly, we detected a shift of the PR spectrum towards higher energies with increasing temperature, indicating the widening of the band gap of CTS in the range of $T=10-130 \mathrm{~K}$, as can be seen in Fig. 4. Measurements at

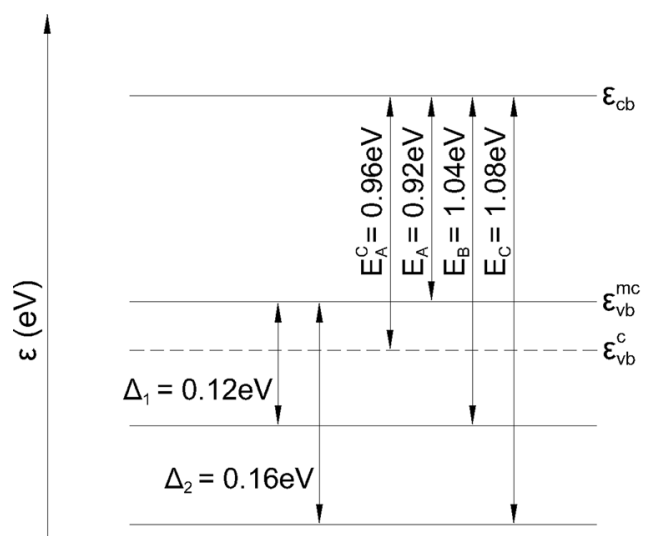

\section{$\mathrm{T}=10 \mathrm{~K}$}

FIG. 3. Band diagram of studied CTS at $10 \mathrm{~K}$, together with optical transition energies and onsets.

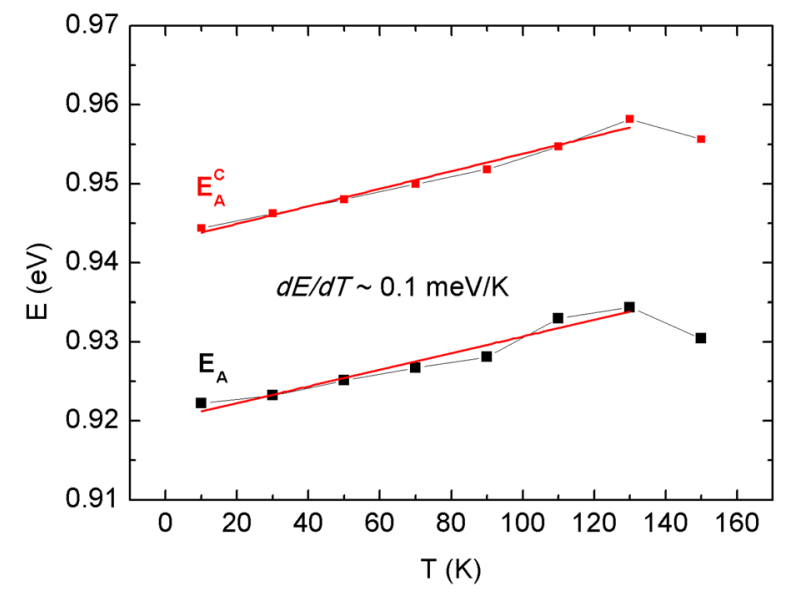

FIG. 4. Temperature dependence of the bandgap energies $E_{A}$ and $E_{A}^{C}$, together with a linear fit (red line).

higher temperatures $(T>150 \mathrm{~K})$ were not possible due to the low PR signal. The bandgap widening with increasing temperature is not very common among the semiconductor materials; however, a similar behavior at low temperatures has also been detected for example in Ag containing ternaries, ${ }^{18}$ black phosphorus, ${ }^{24}$ some chalcogenides $\left[\mathrm{CuInS}_{2},{ }^{25}\right.$ $\mathrm{CuInSe}_{2}{ }^{26}$ and $\mathrm{CuGaSe}_{2}{ }^{26}$ ], and hybrid perovskites. ${ }^{27}$ The blueshift of the free exciton PL band of CTS with increasing temperature was also witnessed by Aihara et al. ${ }^{7,8}$ The observed widening of the energy gap appears to be the result of the competition between the thermal expansion and the electron-phonon interaction. ${ }^{25}$ For example, the thermal expansion coefficient at low temperatures can become negative due to the reduction in the unit cell volume, causing a blueshift of bandgap with increasing temperature. ${ }^{28}$ This was seen for example in $\mathrm{CuBr}$ by Lewonczuk et al. ${ }^{29}$ However, the origin of the blueshift of the bandgap energy of CTS is not yet clarified and needs to be studied further.

In conclusion, a photoreflectance study of a CTS thin film grown by PLD was performed in the temperature range from 10 to $150 \mathrm{~K}$. From the PR spectra, three lowtemperature $(\mathrm{T}=10 \mathrm{~K})$ optical transitions of monoclinic CTS at $E_{A}=0.92 \mathrm{eV}, E_{B}=1.04 \mathrm{eV}$, and $E_{C}=1.08 \mathrm{eV}$ were found. An additional optical transition at $E_{A}^{C}=0.94 \mathrm{eV}$ was attributed to the band gap of cubic CTS. All the identified optical transition energies showed the blueshift with increasing temperature, and the temperature coefficient was $\sim 0.1 \mathrm{meV} / \mathrm{K}$.

This work was supported by the institutional research funding project IUT 19-28 of the Estonian Ministry of Education and Research, by the European Union through the European Regional Development Fund, Project TK141, by FP7 project CHEETAH, EC Grant Agreement No. 609788, and a grant from the Danish Council for Strategic Research.

${ }^{1}$ M. Nakashima and M. Izaki, Appl. Phys. Express 8, 042303 (2015).

${ }^{2}$ P. A. Fernandes, P. M. P. Salomé, and A. F. da Cunha, J. Alloys Compd. 509, 7600 (2011).

${ }^{3}$ H. Guan, H. Shen, C. Gao, and X. He, J. Mater. Sci. Mater. Electron. 24, 1490 (2013).

${ }^{4}$ R. Bodeux, J. Leguay, and S. Delbos, Thin Solid Films 582, 229 (2015).

${ }^{5}$ M. Bouaziz, J. Ouerfelli, S. K. Srivastava, J. C. Bernède, and M. Amlouk, Vacuum 85, 783 (2011). 
${ }^{6}$ L. L. Baranowski, P. Zawadzki, S. Lany, E. S. Toberer, and A. Zakutayev, Semicond. Sci. Technol. 31, 123004 (2016).

${ }^{7}$ N. Aihara, K. Tanaka, H. Uchiki, A. Kanai, and H. Araki, Appl. Phys. Lett. 107, 032101 (2015).

${ }^{8}$ N. Aihara, Y. Matsumoto, and K. Tanaka, Appl. Phys. Lett. 108, 92107 (2016).

${ }^{9}$ L. L. Baranowski, K. McLaughlin, P. Zawadzki, S. Lany, A. Norman, H. Hempel, R. Eichberger, T. Unold, E. S. Toberer, and A. Zakutayev, Phys. Rev. Appl. 4, 044017 (2015).

${ }^{10}$ J. de Wild, E. Kalesaki, L. Wirtz, and P. J. Dale, Phys. Status Solidi RRL 11, 1600410 (2017).

${ }^{11}$ D. M. Berg, R. Djemour, L. Gütay, S. Siebentritt, P. J. Dale, X. Fontane, V. Izquierdo-Roca, and A. Pérez-Rodriguez, Appl. Phys. Lett. 100, 192103 (2012).

${ }^{12}$ J. A. Marquez Prieto, S. Levcenko, J. Just, H. Hampel, I. Forbes, N. M. Pearsall, and T. Unold, J. Alloys Compd. 689, 182 (2016).

${ }^{13}$ S. Fiechter, M. Martinez, G. Schmidt, W. Henrion, and Y. Tomm, J. Phys. Chem. Solids 64, 1859 (2003).

${ }^{14}$ A. Crovetto, R. Chen, R. B. Ettlinger, A. C. Cazzaniga, J. Schou, C. Persson, and O. Hansen, Sol. Energy Mater. Sol. Cells 154, 121 (2016).

${ }^{15}$ Y. T. Zhai, S. Chen, J. H. Yang, H. J. Xiang, X. G. Gong, A. Walsh, J. Kang, and S. H. Wei, Phys. Rev. B - Condens. Matter Mater. Phys. 84, 075213 (2011).

${ }^{16}$ P. A. Fernandes, P. M. P. Salomé, and A. F. da Cunha, Phys. Status Solidi C 7, 901 (2010)
${ }^{17}$ T. Raadik, M. Grossberg, J. Raudoja, R. Traksmaa, and J. Krustok, J. Phys. Chem. Solids 74, 1683 (2013).

${ }^{18}$ T. Raadik, J. Krustok, and M. V. Yakushev, Phys. B: Condens. Matter 406, 418 (2011).

${ }^{19}$ R. Kudrawiec, J. Misiewicz, Q. Zhuang, A. M. R. Godenir, and A. Krier, Appl. Phys. Lett. 94, 151902 (2009).

${ }^{20}$ C. M. Lai, F. Y. Chang, C. W. Chang, C. H. Kao, H. H. Lin, G. J. Jan, and J. Lee, Appl. Phys. Lett. 82, 3895 (2003).

${ }^{21}$ R. B. Ettlinger, A. Crovetto, S. Canulescu, A. Cazzaniga, L. Ravnkilde, T. Youngman, O. Hansen, N. Pryds, and J. Schou, Appl. Phys. A 122, 466 (2016).

${ }^{22}$ A. Shigemi, T. Maeda, and T. Wada, Phys. Status Solidi 252, 1230 (2015).

${ }^{23}$ D. E. Aspnes, "Optical properties of solids," in Handbook on Semiconductors (North-Holland Publishing Company, Amsterdam, 1980), Vol. 2.

${ }^{24}$ C. E. P. Villegas, A. R. Rocha, and A. Marini, Nano Lett. 16, 5095 (2016).

${ }^{25}$ J. H. Hsu and T. M. Lin, Phys. Rev. B 37, 4106 (1988).

${ }^{26}$ C. Lárez, C. Bellabarba, and C. Rincón, Appl. Phys. Lett. 65, 1650 (1994).

${ }^{27}$ M. A. Green, A. Ho-Baillie, and H. J. Snaith, Nat. Photonics 8, 506 (2014).

${ }^{28}$ D. T. Kim, M. S. Jin, and W. T. Kim, J. Korean Phys. Soc. 47, 331 (2005).

${ }^{29}$ S. Lewonczuk, J. G. Gross, and J. Ringeissen, J. Phys. Lett. (Paris) 42, 91 (1981). 